\title{
Estudos da infância, antropologia e etnografia: potencialidades, limites e desafios ${ }^{1}$
}

\author{
Manuela Ferreira \\ Faculdade de Psicologia e Ciências da Educação e \\ Centro de Investigação e Intervenção Educativa \\ Ấngela Nunes \\ Centro em Rede de Investigação Antropológica
}

\section{Resumo}

Partindo da etnografia como denominador metodológico comum aos campos dos estudos da infância e da antropologia e subscrevendo a sua importância para conhecermos as crianças a partir delas mesmas, o presente artigo visa a abordar as potencialidades desta abordagem, dando a conhecer contributos oriundos destes campos disciplinares; refletir acerca dos efeitos colocados por limites, como os etários e espaço-temporais; e identificar alguns dos desafios que hoje em dia se colocam à pesquisa etnográfica com crianças.

Palavras-chave: Estudos da infância. Antropologia. Etnografia. Epistemologia.

1. Uma versão inicial deste texto foi apresentada na Conferência Internacional “The doors of perception: Viewing anthropology through the eyes of children", 2010, VU University, Amsterdã. 


\section{Childhood studies, anthropology and ethnography: potentialities, limits and challenges}

Considering ethnography as a methodological common denominator to Childhood Studies and Anthropology and subscribing its importance in getting to know children from their own perspective, this article aims to address the potentialities of this approach presenting contributions from both disciplinary fields; reflect on the effects placed by certain limits such as those related to age and space-time, and identify some of the challenges faced today when conducting ethnographic research with children.

Keywords: Childhood studies. Anthropology. Ethnography. Epistemology.

\section{Estudios de la infancia, antropología y etnografía: potencialidades, límites y desafíos}

Teniendo en cuenta la etnografía como denominador común metodológico para los estudios sobre la niñez y la Antropología, y la suscripción de su importancia para conocer a los niños en su propio punto de vista, este artículo tiene como objetivo abordar el potencial de este enfoque presentando las contribuciones de los dos campos de estudio, reflexionar sobre los efectos formulados por algunos límites, como las dimensiones de edad y en el espacio-tiempo, e identificar algunos de los desafíos que enfrentan hoy en día a tomar la investigación etnográfica con los niños.

Palabras clave: Estudios de la infancia. Antropología. Etnografía. Epistemología. 


\section{Apresentação}

Um dos desafios que os estudos sociais da infância colocam aos adultospesquisadores interessados em conhecer as crianças como atores sociais que efetivamente têm uma determinada agency é o de porem mãos à obra e tentarem descobrir qual é ela pelo uso da etnografia (James; Prout, 1997; James; Jenks; Prout, 1998; Prout, 2005). A assunção e a importância deste postulado, em que o estatuto das crianças como atores sociais com "voz" própria é reconhecido, não pode ser dissociadas do contexto sócio-histórico de afirmação e ratificação da Declaração dos Direitos das Crianças (1989), nem do marco temporal e epistemológico representado pela emergência e consolidação dos estudos da infância. 0 acervo de conhecimento, entretanto, acumulado acerca da diversidade e complexidade dos mundos sociais das crianças e da pluralidade de infâncias parece ser revelador do sucesso de tal missão, como atestam recensões recentes realizadas em diversos países².

No entanto, isso não significa que a etnografia presente nos estudos da infância esteja ou seja isenta de problemas epistemológicos, teóricos, metodológicos e éticos, que acarretam consequências para a compreensão da construção social da infância e para o próprio conhecimento que é gerado (James, 2007; Tisdall; Punch, 2012). Esta questão torna-se ainda mais problemática porquanto nos textos acadêmicos nem sempre é visível a reflexividade inerente e emergente da prática etnográfica, essencial para esclarecer os processos de produção de conhecimento e repensar o contributo desta abordagem na contemporaneidade e nas várias disciplinas das ciências sociais. Daí que "certos mantras teóricos (construção social da infância e as crianças como atores sociais) e metodológicos (o foco na ética, privilegiando as "vozes", a etnografia e os estudos micro)" (Tisdall; Punch, 2012, p. 259) deste campo de estudos interdisciplinar pareçam ser dominados e/ou apropriados mais ou menos acriticamente, refletindo não apenas a variabilidade decorrente das especificidades sociais e tradições acadêmicas dos diferentes países, como a sua maior ou menor familiaridade com a etnografia e seus debates internos. Veja-se o caso inglês em que os estudos da infância continuam a ser dominados pela sociologia, antropologia e geografia da infância. (Tisdall; Punch, 2012), ao passo que nos países lusófonos parece sobressair o campo da educação (Nunes, 1999; 2003; Rocha, 1999; Ferreira; Rocha, 2009; 2012; 2013; Colona, 2011; Martins Filho, 2011; Delgado, 2011; Szulc; Cohn, 2012)

Neste seguimento, em face de alguns paradoxos e problemas inerentes às

2. Por exemplo, cf. número especial da revista Current Sociology, mar. 2010 (2), acerca do estado da arte em dez países: Austrália, Brasil, Finlândia, França, Alemanha, Itália, Holanda, Inglaterra, Romênia e EUA. Para o caso português, cf. Ferreira; Rocha (2009; 2012; 2013). 
práticas etnográficas que acompanhamos ou experimentamos em campos disciplinares e contextos diferentes, visamos a prosseguir o desafio lançado há mais de 20 anos, mas que se mantém atual (Prout, 2005; James, 2007), de interrogar e repensar os modos como a etnografia, com todo o seu potencial, mas também os limites e desafios que coloca e que se lhe colocam, tem contribuído para conhecermos as crianças e a infância. Posto isso, com base em recensões recentes de âmbito internacional, incluindo o caso lusófono, relativas aos estudos da infância, começamos por empreender uma breve recapitulação da importância que a etnografia, como metodologia de eleição, aí assume, para depois evidenciarmos a contribuição específica, mas até agora ainda discreta, dos estudos antropológicos (James, 2001; 2007; LeVine, 2007; Lancy, 2009; Nunes; Carvalho, 2009), para e nesta abordagem interdisciplinar. Seguidamente, colocamos questões epistemológicas, teórico-metodológicas e éticas, concentrando-nos na presença de um viés metodológico, transversal à produção etnográfica que se tem vindo a realizar no âmbito dos estudos da infância, em que se constata a baixa incidência de estudos com crianças menores e uma série de limites espaço-temporais que afetam o trabalho etnográfico no atual cenário da pesquisa científica. Isto conduz, por fim, à chamada de atenção para alguns desafios que se colocam à etnografia com crianças.

\section{Etnografia: entre estudos da infância e antropologia}

O propósito de conhecer a realidade contemporânea a partir da infância e das interpretações e interpelações das próprias crianças acerca das suas circunstâncias de vida e do mundo social, referido pelos estudos da infância, visa a romper com uma visão científica dominante, historicamente sustentada nas disciplinas fundadoras da reflexividade científica sobre as crianças nas ciências sociais: medicina, psicologia e educação. Como legados desta visão ressaltamos: a tendência para dicotomizar os aspectos sociais e culturais da infância dos seus aspectos biológicos; a hipervalorização dos conceitos de desenvolvimento e de socialização, e modos de pesquisa empírica que examinam as crianças como objetos ou como sujeitos imperfeitos e "suspensos" da realidade social. (Christensen; James, 2000)

0 reconhecimento de outro estatuto às crianças como atores sociais tem radicado na defesa de uma agenda de pesquisa que, entre outras premissas, vê no uso da etnografia um contributo inestimável ao debate epistemológico, teóricometodológico e ético em curso nas múltiplas disciplinas das ciências sociais integrantes dos estudos da infância. Este desafio sustenta-se no argumento de que 
a etnografia "permite à criança uma participação e voz mais diretas na produção de dados sociológicos do que normalmente é possível através das pesquisas experimentais" (James; Prout, 1997, p. 8-9). Tal significa que nas pesquisas em que se tomam as crianças como atores sociais elas são a unidade de estudo direto e basilar, a sua autonomia e equidade conceptual é assumida como legítima, as suas interações sociais são a unidade de análise privilegiada e é respeitado o princípio da simetria ética com os adultos ${ }^{3}$ (Thorne, 1993; James; Prout, 1997; Qvortrup, 1996; Corsaro, 1997; Christensen; James, 2000; Prout, 2002). 0 propósito é revelar a agência das crianças nos constrangimentos e possibilidades que vivem nas suas vidas, reconhecendo-as como (re)produtoras de sentido e com o direito de se apresentarem como sujeitos de conhecimento nos seus próprios termos. Não se trata de defender a corrida a etnografias concentradas nas crianças, como afirma Toren (2002), mas que se considerem as crianças tão importantes como qualquer indivíduo de outra idade:

As crianças deveriam ser centrais à análise etnográfica simplesmente porque estão destinadas, ao longo do tempo, a constituir um saber sobre as práticas dos adultos e as ideias que estes usam para as justificar. (...) apenas [as crianças] podem nos dar acesso ao que elas sabem sobre o mundo e as pessoas, e o que elas sabem pode darnos elementos para uma compreensão analítica que não podem ser obtidos de nenhum outro modo. (Toren, 2002, p. 113)

Escutar a(s) voz(es) das crianças constitui, portanto, no plano epistemológico, uma questão nodal. Por um lado, porque se assumem como legítimas as suas formas de comunicação e relação, mesmo que se expressem diferentemente dos adultos. Por outro, porque se considera relevante que o que elas têm a dizer aos adultos são contributos importantes sem os quais a compreensão da vida em/ nas sociedades seria incompleta. E ainda porque tudo isso significa, afinal, que os adultos só poderão ter acesso a esse pensamento e conhecimento se estiverem na disposição de inverter a sua posição na relação tradicional de pesquisa e suspenderem os seus entendimentos e cultura adultos para, na medida do possível, aprenderem com elas os delas, ou seja, para compreenderem a compreensão do outro-crianças, tal como advoga a etnografia reflexiva. Em causa estão, portanto, as relações inter e intrageracionais, e o (re)conhecimento da infância com base na interdependência e alteridade que permeiam as identidades adultas e infantis nos seus encontros intersubjetivos.

3. As crianças são seres humanos semelhantes aos adultos, possuindo competências diferentes e legítimas (Christensen; James, 2000, p. 481). Ao nível metodológico, o princípio básico é proceder tal como nas pesquisas com adultos (Idem, p. 484). 
Esta agenda teórico-metodológica tem-se traduzido na valorização do diálogo interdisciplinar, na aposta em estudar os cotidianos e apreender as perspectivas das crianças nos contextos institucionais de educação escolar e familiar, mas também na ampliação do estudo dos seus mundos sociais a outros espaços socioeducativos para além, e entre, a escola e a família. Tem-se traduzido também num esforço para analisar as suas interações de um modo mais denso, refinado e crítico, pela inclusão dos efeitos sociais das dimensões estruturais de classe, gênero, etnia, religião, de outras culturas e da cultura globalizada para a infância e, assim, evidenciar as qualidades prismáticas da tão falada agência das crianças, seja naquilo que têm de produção cultural, de reprodução ou ambiguidade social (Tisdall; Punch, 2012, p. 256). A desocultação da complexidade dos processos de socialização, da diversidade de experiências sociais das crianças e da pluralidade de infâncias, da heterogeneidade de formas, estilos e lógicas em que se exprime a sua agência nas interações intra e intergeracionais, bem como da teia de sentidos que aí se investem e negociam lestratégias, transgressões, resistências, transformações, mas também conformidade e reprodução), são alguns dos dados postos a descoberto através da descrição densa (Geertz, 1978, p. 13-41) e dos textos etnográficos. A natureza desta intensa vida social, substanciando outras bases informativas, analíticas, teóricas, metodológicas e éticas necessárias à crítica da reflexividade científica dominante, atesta o potencial epistemológico da etnografia para conhecer o que é distintivo e singular deste/neste grupo geracional e para interrogar o conhecimento e a teoria disponíveis acerca das crianças e, com isso, ampliar ainda as possibilidades de vir a conhecer e interrogar a condição social dos adultos como adultos.

Ora, avaliando-se o potencial da etnografia pela recorrência com que tem surgido no âmbito das várias disciplinas ${ }^{4}$ que integram os estudos da infância, isso não significa nem igual volume, nem igual visibilidade em cada uma delas. Torna-se assim paradoxal a crescente visibilidade, e popularidade até, que a etnografia tem alcançado no campo da educação, corroborando o interesse de eleger as crianças e a infância como pivôs para a análise social da realidade, e a presença ainda discreta dos estudos elaborados no campo da antropologia, onde a etnografia é declarada como uma metodologia de excelência, fundante da disciplina.

4. Entre outros, destacamos a Sociologia (Corsaro, 1995; Ferreira, 2002; Scalabrin, 2010), Antropologia (James, 1993; Nunes, 1999; 2003; Delalande, 2001), Geografia (Holloway, Valentine, 2000), Estudos de Gênero (Davies, 1989; Thorne, 1993) e Educação (Scalabrin, 2002; Pires, 2004; Guimarães, 2011). 


\section{Impacto dos estudos antropológicos nos estudos da infância}

David Lancy (2012), antropólogo americano que alude a uma "marginalização" da antropologia nos estudos realizados sob a égide do que ele, de forma crítica, chama "Children's Agency Movement" 5 , afirma que na sua análise do enorme número de etnografias antropológicas realizadas desde o início do século XX até os dias de hoje, tudo o que encontra sobre crianças e infância é útil à sua compreensão nas mais diversas sociedades.

0 trabalho de recenseamento realizado no âmbito da antropologia tem trazido à tona um conjunto insuspeitável de pesquisas produzidas anteriormente à eclosão da revisão epistemológica formalizada no paradigma de James; Prout, nas quais as crianças e a infância estão presentes. É já no final do século XIX que antropólogos evolucionistas, escritores e viajantes esboçam os primeiros sinais do que se viria a identificar como o potencial da etnografia para o estudo da infância. Nas primeiras décadas do século XX, pesquisadores da escola americana de estudos da cultura e personalidade revelam um notório interesse sobre a infância, alertando para a influência da cultura no processo de crescimento das crianças $^{6}$. Entre estes últimos, destaca-se Margaret Mead, que recolheu e deu forma ao maior conjunto de dados etnográficos até hoje existente sobre a infância em sociedades não ocidentais, e introduziu uma enorme inovação no modo de estudar a infância e a adolescência: a observação continuada e a participação no dia a dia nas aldeias onde pesquisava. A influência dos estudos culturalistas, prolongada até aos anos 1970/1980 e somada aos estudos sobre o grupo doméstico e ciclo de vida do indivíduo, produziu um enorme e relevante acervo etnográfico sobre a infância e as crianças nas mais diversas sociedades ${ }^{7}$. Isto, mas também o caráter disperso e descontínuo desta produção, é reafirmado em recensões recentes dos antropólogos Hirschfeld (2002); LeVine (2007)8; Lancy (2009). Sobre o elevado número de registros etnográficos sobre crianças e infância, Hirschfeld (2002, p. 611) ressalva que, todavia “[...] Este trabalho não se fundiu numa tradição sustentada na pesquisa focada na criança. Nem, como um coro de pesquisadores tem lamentado (Caputo, 1995; Hardman, 1973; Toren, 1993), conseguiu trazer as

5. Cf. Lancy (2012), relativamente às críticas à afluência de estudos que dogmaticamente se referem à agência das crianças, sem refletirem sobre o caráter "etnocêntrico, classista e hegemônico", representando a educação burguesa dominante na contemporaneidade.

6. Ver referência aos antropólogos evolucionistas e culturalistas em Nunes (1999; 2003).

7. Cf. Nunes (2003, p. 39-54) sobre a contribuição de Mead e as críticas ao seu trabalho, e outras contribuições da antropologia (Goody; Fortes,; LeVine) e da psicologia (Whiting, entre outros). Cf. também recensão de Nunes; Carvalho (2009).

8. 0 acervo referenciado por LeVine (2007), incidindo nas práticas do cuidar lamamentação, higiene, comportamentol e sobre o brincar, além de pouco conhecido pelos pesquisadores europeus, parece disperso e de difícil acesso. 
crianças das margens para o centro da antropologia. Já a recolha de Lancy 12009 , p. IX) teve como objetivo

incluir, portanto, o trabalho de antropólogos interessados na infância que, até então, podem não ter tido conhecimento ou, pelo menos, não ter apreciado os trabalhos uns dos outros. [...] Deve servir como um catalisador que promove maior interação entre aqueles que estudam as crianças.

Nas revisões críticas da literatura antropológica elaboradas por James (2001, 2007) ${ }^{9}$, embora reconheça que os estudos etnográficos até a década de 1990 sejam de um enorme valor e que criaram uma espécie de plataforma para alicerçar o novo paradigma, onde a etnografia surge como método de eleição, considera que nestes as crianças constituem uma espécie de epifenômeno, ou fenômeno adjacente a um dado objeto de estudo, e não uma entrada para a compreensão da vida em sociedade e da cultura.

A virtude de todas estas recensões é a evidente antiguidade, quantidade e diversidade de material etnográfico existente, ao mesmo tempo em que o seu maior óbice parece ter sido, e talvez ainda seja, o seu caráter disperso e descontínuo, e o desconhecimento que sobre ele existia até recentemente. A história do estudo da infância e das crianças na antropologia parece ter sido assim marcada não por uma ausência de interesse pelas crianças e a infância, mas pela dificuldade em reunir, dar visibilidade, divulgar e refletir sobre este acervo em tempo útil, inibindo processos que permitiriam a construção de um referencial teórico e metodológico específico, com impacto no seio da disciplina e fora dela. (Nunes 1999; 2003)

\section{Limites na etnografia com crianças}

As observações até agora esboçadas convidam a refletir sobre a atual produção de etnografias com crianças no âmbito dos estudos da infância, indo além da reiteração do seu indiscutível aumento. Um olhar atento rapidamente identifica um viés etário e contextual recorrente: as idades escolares e os espaços-tempos institucionais formais têm sido e continuam a ser sobrevalorizados em detrimento de outras idades, contextos e circunstâncias que, relevantes do ponto de vista sociocultural, não são necessariamente escolares. Independentemente da área disciplinar, a abundância de etnografias com crianças de idade igual ou maior de

9. Elaboradas numa perspectiva sócio-histórica, estas recensões são o exemplo de abordagem interdisciplinar transcontinental mais abrangente, que apresenta uma visão crítica de como nas obras analisadas crianças e infância foram e são conceptualizadas. 
7 anos realizadas em escolas (entre outros, Derouet; Henriot-Van Zanten; Sirota, 1987; Gordon; Holland; Lahelma, 2001; James, 2001; 2007; Silva, 2007; Ferreira; Rocha, 2010) contrasta com uma incipiente expressão quantitativa de etnografias com crianças pequenas (3-5/6 anos) (entre outros, Corsaro, 1985; Davies, 1989; James, 1993; Delalande, 2001; Ferreira, 2002) e a quase ausência de etnografias com crianças menores (0-2/3anos) (entre outros, Gottlieb, 2000; Scalabrin, 2002; 2010; Camera, 2006; Schmitt, 2008; Guimarães, 2011110. Outro traço comum das pesquisas com crianças pequenas é que, majoritariamente, optam pelas idades mais velhas dos recortes etários, e circunscrevem-se a contextos institucionais educativos reservados à infância contemporânea ocidental, como creches e jardins de infância.

Intersetando um conjunto de questões teóricas, metodológicas e éticas, refletimos em seguida acerca dos limites etários e espaço-temporais colocados à realização de pesquisa etnográfica na contemporaneidade.

\section{Limites etários: a "ausência" de crianças pequenas}

A menor incidência de etnografias com crianças em idades anteriores à escolar suscita interrogações e reflexões em torno dos critérios e processos de categorização e seleção que presidem à construção dos terrenos etnográficos considerados relevantes pelos pesquisadores, e também das concepções de crianças e infância que os informam. Que razões estão na base deste viés etário, quando hoje em dia as crianças ingressam cada vez mais precocemente nas instituições educativas e se expandem as políticas e serviços educativos a estas idades? Que consequências esta institucionalização da vida coletiva das crianças nas sociedades contemporâneas ocidentais acarreta para as suas formas de relação e entendimento do mundo? Que conhecimento oriundo das etnografias com crianças é produzido quando uma "fatia" constitutiva da infância, crianças dos 0-6 anos, parece não merecer a sua atenção? Até que ponto esta ausência contribui para a manutenção da sua invisibilidade social? O que leva os pesquisadores, independentemente do seu campo disciplinar, a serem tão consistentemente seletivos? Os limites da linguagem verbal e competências comunicacionais das crianças pequenas, bem como das suas capacidades cognitivas e de compreensão,

10. 0 número crescente de etnografias ou pesquisas de inspiração etnográfica com bebês e crianças pequenas

(0-6a) realizadas no Brasil (cf., entre outros, Rocha; Kramer, 2011; Martins Filho, 2011; Guimarães, 2011) contrasta com o caso português. Para uma recensão crítica das pesquisas autodesignadas na Sociologia da Infância e/ou como etnografias, realizadas em Portugal entre 1995-2005, (cf. Ferreira; Rocha, 2009; 2010; 2012; 2013.J 
mais a sua pouca experiência social, são, de acordo com Alderson (2004), alguns dos argumentos geralmente mobilizados pelos pesquisadores para as evitarem - dúvidas, dificuldades e reticências tendentes ainda a expressar um agravo tanto maior quanto menores elas forem.

Radicando frequentemente em apropriações e interpretações anacrônicas mas hegemônicas de pressupostos e assunções oriundos da psicologia do desenvolvimento da criança, particularmente do desenvolvimento intelectual, aqueles argumentos subentendem, de acordo com Birbeck; Drummond (2005), três grandes impedimentos - a falibilidade da sua memória, o seu egocentrismo e a sua sugestionabilidade -, independentemente das inúmeras críticas que entretanto têm surgido dentro deste próprio campo (Woodhead, 2009). Com base na análise crítica daqueles impedimentos em estudos apoiados por metodologias experimentais controladas e por metodologias qualitativas, Birbeck e Drummond (2005, p. 582) concluíram que em relação à fiabilidade da memória:

Os erros tendem a assumir a forma de omissões ou fatos esquecidos em vez de serem incorretos no detalhe [...]; que as crianças são mais bem-sucedidas que os adultos quando são questionadas acerca de informações sobre as quais têm maior conhecimento que aqueles [...]; que a sua fiabilidade aumenta quando são questionadas acerca de assuntos que são relevantes e significativos para elas, [e que] as crianças são capazes de relembrar eventos na ordem temporal quando aqueles thes são familiares.

Advogam assim que, "se o efeito do tempo na memória das crianças tem impacto na quantidade de informações, a necessidade de as escutar é ainda mais imperativa" (Birbeck; Drummond, 2005, p. 582-583). Do mesmo modo, contestam - conceito de egocentrismo como sinônimo de fragilidade moral lfalta de preocupação com o impacto das suas ações) e cognitiva (incapacidade de apreciar o ponto de vista do outro e memória seletiva para informação que tem significação pessoal), e a sugestão de que este se manifesta na ideia de que as crianças dizem mais mentiras que os adultos. Na sua argumentação, afirmam: i) que a verdade implica relatar fatos, ou o que aconteceu, tal como a pessoa o percebeu; ii) que a percepção e memória são processos subjetivos; e iii) que a delimitação do que constitui um evento central de um periférico numa dada situação depende do olhar do observador, independentemente da sua idade. Os autores referem ainda estudos dando conta de que as crianças com 3 ou 4 anos: i) entendem a diferença essencial entre verdade e mentira; ii) tendem a reportar a informação que percebem ser central, omitindo a periférica; iii) tendem a mentir para evitar a punição, sendo que, afinal; iv) o mentir em cada idade tende a ser mais uma resposta a fatores situacionais do que um traço específico do caráter (Birbeck; Drummond, 2005, p. 
583). Por conseguinte, crianças e adultos dizem mentiras, não havendo provas de que as crianças o façam mais. Por fim, a questão da sugestibilidade das crianças, pensada como construto relacionado com as suas competências cognitivas e com o diferencial de poder percebido entre estas e o pesquisador, é também rebatida. Os mesmos autores evocam pesquisas experimentais que demonstram que as crianças são resistentes à sugestão e avançam que o importante para aceder a informações fiáveis requer dos pesquisadores uma aceitação não crítica do que as crianças têm para dizer, entendendo que o que elas dizem são indicadores de percepção em vez de uma resposta certa ou errada. (Birbeck; Drummond, 2005, p. 584)

Particular relevância parece assumir então as dimensões socioculturais e econômicas dos contextos em que as interações e relações se estabelecem entre adultos e crianças, o que chama a atenção para as teorias da psicologia sociocultural de Vigotsky (1978); Rogoff (2003), cujo potencial reside na:

Sugestão de que o desenvolvimento, mais do que um desdobramento de uma forma previsível da infância para a adultez através da expressão externa de estruturas biológicas inatas, envolve a participação em processos sociais. Não há desenvolvimento ltal como a progressão piagetiana em direção à racionalidade); pelo contrário, o desenvolvimento depende de objetivos culturais. (Smith, 2002, p. 77; apud Tisdall; Punch, 2012, p. 253)

Assumir um posicionamento teórico crítico das concepções essencialistas e naturalistas que impendem sobre a noção de competência, como se ela se tratasse de algo que se possui ou não, e/ou de que se espera um desabrochar num dado período crítico ou idade, significa não estar esgotado o debate acerca das competências das crianças, sobretudo quando são pequenas.

Importa então situar este conceito para além dos limites e diferenças que possa apresentar em face dos adultos, pelo reconhecimento e inclusão das dependências, incompetências e incompletudes como sendo também constituintes da ação social (Cocks, 2006). Ora, situar as competências das crianças é entendê-las como atores sociais, posicionando a multiplicidade das suas ações nessa indissociabilidade de usos que elas fazem da sua experiência acumulada e das suas competências comunicativas atuais, em função e em relação à rede de contextos e conjunturas em que se movem e em que se dão os seus encontros e desencontros. São estes entendimentos das competências das crianças, incluindo as mais jovens, que justificam a importância dos pesquisadores, através da etnografia, as observarem mais pelo que fazem do que pelo que dizem (Solberg, 1996) para as escutarem e "ser[em] capaz[es] de interpretar, traduzir, mediar os sentidos intersubjetivos possíveis nos processos comunicativos [...], numa postura de cuidado, abertura ao 
outro e deslocação da atenção para a pessoa, na qualidade de pessoa complexa, e não para as categorias sociais que pesam sobre ela" (Ferreira; Rocha, 2010, p. 15). Melhor se compreende assim a proposta de Toren (2002, p. 113):

obter dados sistemáticos de crianças de diferentes idades permite-nos compreender melhor as práticas e ideias das pessoas com quem trabalhamos, porque eles são obrigados a revelar o que os informantes adultos não podem nem dizer nem nos mostrar.

\section{Limites espaço-temporais}

Não obstante as questões contextuais de espaço-tempo pareçam de menor importância nas etnografias com crianças, ambas, crianças e etnografia, estão sob sua influência e de tudo o que estas estruturas representam.

Comecemos pelo acesso às crianças, que, hoje em dia, sobretudo nos espaços urbanos, está cada vez mais limitado aos espaços institucionais: escolas, hospitais, estruturas para ocupação de tempos ditos "livres". Sendo a etnografia nestes espaços sempre mediada pelos adultos, que gerem e decidem sobre o que aí acontece, as implicações epistemológicas na pesquisa são de várias ordens, entre as quais: as relações de poder adulto-criança; o impacto da estrutura institucional e organizacional no modo de recolha etnográfica, no tipo de dados que se recolhem e nas reações e inferências mútuas sobre qualquer assunto, e que podem diferir conforme crianças e pesquisador estão dentro ou fora das instalações, de quem está presente e as acompanha, etc. Num estudo realizado com crianças portuguesas residentes na Alemanha, Nunes (2013) alude a uma longa e demorada burocracia através de autoridades portuguesas e alemãs para que pudesse acompanhar as aulas de língua materna que as crianças frequentavam. Esse espaço-tempo era o único possível para fazer etnografia de modo regular e contínuo, não obstante as faltas dos alunos e a obrigatoriedade das tarefas escolares reduzir a alguns minutos por dia de aula as ocasiões de interação direta das crianças com a pesquisadora. Depois de obter concordância de professores e pais, finalmente conseguiu falar com as crianças: "Quando thes perguntei se concordavam com a minha presença nas aulas e se gostariam de colaborar, antes de terem dito ou perguntado qualquer coisa, a professora respondeu: "Mesmo que eles não queiram, quero eu e está o assunto resolvido!” (Nunes, 2013). No decorrer deste estudo, foi desenvolvido um projeto de intercâmbio com uma escola em Portugal. Aprovado pela Coordenação de Ensino e tendo a participação da professora e a concordância dos pais, as possibilidades de encontro com essas 
crianças, em grupo, fora do espaço escolar, para atividades veiculadas ao projeto, ficaram limitadas pelas autorizações da família, facilidade de deslocamento na cidade, tempo disponível para os pais as acompanharem ou irem levar/buscar e a posse, ou não, de seguros contra eventuais riscos ou danos.

Se um maior acesso às crianças se dá em espaços institucionais públicos, ele continua a ser extremamente limitado quando se trata de espaços institucionais privados e ainda mais de elite, havendo geralmente um apertado inquérito acerca dos objetivos e usos da pesquisa. Em outros espaços privados, mas de caráter comercial, como McDonald's, ou de diversão e/ou para festejar aniversários infantis, acrescem-se às dificuldades de acesso outras que se refletem nas condições de observação e relação com as crianças: mais do que observação participante, o que se torna possível são apenas aproximações e observações diretas de curta duração, de grupos de crianças diferentes que se renovam a cada $2 \mathrm{~h}$ e com quem o pesquisador se encontra pela primeira vez, pontualmente sendo pouco provável novo reencontro (Queirós, 2009). Referem-se, ainda, limitações de acesso à intimidade do espaço familiar e doméstico. Este ocorre, sobretudo, se o pesquisador é familiar ou tem uma relação de proximidade prévia com a família da criança (Colona, 2011). Em outros casos, são visitas pontuais para entrevistas, ou esporádicas em momentos que não fazem parte do cotidiano, como festas de aniversário. (Ferreira; Rocha, 2000)

Já as dificuldades de acesso às crianças em espaços não institucionais, públicos e abertos (ruas, parques nas cidades e bairros) são de outra ordem: não sendo a princípio regulada, a nossa presença não é menos facilitada, sobretudo se não se dispuser de "porteiros" locais facilitadores da aproximação. Levantam-se assim problemas metodológicos e éticos que implicam logo uma justificação credível do que se está fazendo ali, sob pena da simples presença de um adulto desconhecido observando crianças poder ser considerado por muitos adultos, e mesmo pelas crianças, como perigoso ou ameaçador (pedofilia, desaparecimentos, sequestros, etc.). 0 elemento periculosidade pode ainda ser extensível aos pesquisadores em determinados contextos geossociais (não sendo o gênero e idade negligenciáveis), porque mais expostos e alvos fáceis de roubo ou agressão ${ }^{11}$. Ultrapassados estes problemas no contato inicial, nada garante, no entanto, que a sua presença seja aceita de modo incondicional por todas as crianças presentes e, ainda menos, que aquele primeiro encontro se mantenha com alguma regularidade. A presença das crianças nestes espaços, descontínua consoante a estação do ano, dia da semana ou hora do dia, restringe a observação ${ }^{12}$ e coloca o pesquisador numa posição de

11. Informação de Samy Lansky, em comunicação pessoal.

12. Este problema pode também ocorrer em outros contextos: pediatrias de hospitais, ruas e espaços públicos de bairros. 
dependência e vulnerabilidade. Lidar com a variabilidade das condições espaciais exige, assim, uma imensa disponibilidade de tempo para se conhecerem as possíveis combinações espaço-tempo das crianças. (Pires, 2005; Colona, 2011; Nunes, 2013)

Perante os limites que acabamos de expor, e que são parte da realidade vivida no cotidiano de qualquer pesquisado que recorra à prática etnográfica, cabe ainda perguntar: que possibilidade de contato direto com as crianças existe nos espaços institucionais altamente estruturados, mediados e controlados pela autoridade adulta? Como é que se estabelecem as necessárias relações de familiaridade com grupos de crianças heterogêneos e altamente mutáveis, em espaços abertos e não formais, e em circunstâncias de tempos pontuais e fugazes, marcados pela descontinuidade? Como fazer etnografia com recursos e tempos cada vez mais reduzidos de permanência no terreno? Em causa está o respeito por princípios epistemológicos, teóricos, metodológicos e éticos inerentes à prática da observação participante e a sua compatibilização com as novas exigências da produção científica que requerem, simultaneamente, uma maior quantidade e velocidade de execução. Se uma das condições para efetuar etnografia é a estadia continuada e prolongada no terreno, pois só ela permitirá a familiaridade com o contexto de pesquisa e seus sujeitos, esta parece ficar inviabilizada pelas atuais condições de realização da pesquisa científica.

\section{Considerações finais: desafios à etnografia com crianças}

Apesar de toda a ênfase colocada na abordagem das crianças como atores sociais, o périplo que percorremos até aqui evidencia como há diferenças substanciais entre as agendas teóricas, a sua abordagem metodológica e a diversidade humana infantil; como a realidade é sempre mais complexa do que os conceitos e concepções usados para a descrever; como as opções metodológicas não são neutras nem isentas de consequências científicas e sociais; e como os modos de entendimento e classificação das crianças na infância interferem, objetiva e subjetivamente, nas escolhas dos pesquisadores.

A presença do viés etário referido chama a atenção para a necessidade de se consciencializarem e problematizarem: i) as diferenças intrageracionais que integram a categoria infância; ii) as ordenações hierárquicas e desiguais que coexistem e são transversais às relações entre e intragerações; iii) as questões teóricas inerentes ao conceito de infância, cuja complexidade implica considerálo como categoria sócio-histórica geracional, internamente plural, heterogênea e desigual, e como espaço social em que as crianças vivem as suas experiências 
como crianças; iv) a noção de idade como modo de classificação e representação social com relevo descritivo e analítico; vl as justificações que subsidiam os critérios de seleção dos sujeitos empíricos a observar.

$\mathrm{Na}$ intencionalidade que procura captar os pontos de vista das crianças, mas que, ainda assim, continua a evitar as mais jovens, outro contributo importante da etnografia consiste em alimentar a reflexão em torno do conceito de socialização. Sendo este um dos "cavalos de batalha" dos estudos da infância, relembra-se a crítica à concepção adulta do conceito de socialização herdada da tradição Durkheimiana:

A concepção das crianças como sendo essencialmente deficientes vis-à-vis aos adultos, tem, na prática, conduzido à não pesquisa sobre crianças qua crianças e isso tem servido para, cientificamente, autorizar as concepções do senso comum acerca das crianças como incompletas. (Mackay, 1991, p. 28)

Também para Toren, este conceito não pode ser pensado como processo previsível e meramente reprodutor do mundo adulto. Advogando uma perspectiva histórica, na qual está implícita a ideia de mudança ou transformação social, considera que compreender a participação das crianças na vida social "exige [a sua] focalização [...] como sendo, ao mesmo tempo, sujeitos e objetos da história”. (Toren, 1993, p. 462)

Neste deslocamento da atenção para as crianças que, no terreno das relações etnográficas, corre a par da necessária inversão da relação tradicional de pesquisa, a desmistificação vs. problematização da sua agência (Tisdall; Punch, 2012, p. 255-256) tem ainda desafiado à inclusão das suas vulnerabilidades e incompletudes e à releitura da interdependência ser-tornar-se criança (Uprichard, 2008). Neste seguimento, os processos de reflexividade metodológica inerentes à prática etnográfica constituem terreno fértil para ampliar a problematização do conceito de agência aos adultos, desafiando-os a perspectivarem o conceito de adultez nas diferenças, alteridade e interdependências intergeracionais, segundo um entendimento de ambas as condições, adulto e crianças, como identidades em construção, transitórias e múltiplas. (Johansson, 2011)

Estes dilemas teórico-metodológicos e éticos desafiam-nos a enfrentar os problemas de autenticidade e de representação nos estudos contemporâneos sobre infância (James, 2007). Ao que tudo indica, as crianças passaram a "falar" como sujeitos participantes, mas revelar e tornar essas vozes audíveis através dos textos etnográficos requer uma reflexão mais ampla sobre a sua tradução, interpretação e mediação; tarefa tanto mais difícil quanto mais novas as crianças são, pois mais distantes estão do discurso próprio da lógica adulta. E se as "vozes" que são registradas forem dissonantes em relação ao que entretanto e de certa 
forma dogmaticamente se considera serem as "vozes das crianças"? James alerta para o risco de generalização, de reprodução acrítica do que é registrado como as "vozes das crianças", e uso como instrumento retórico para fins que lhes são distantes:

Pesquisar a infância não é simplesmente tornar as vozes das crianças audíveis, no sentido mais literal, através da apresentação das suas perspectivas. Trata-se, também, de explorar a natureza da voz atribuída às crianças, como esta molda e reflete o modo como a infância é entendida e, portanto, os discursos no âmbito dos quais as crianças se localizam em qualquer sociedade. (James, 2007, p. 266)

Assumir este aviso-desafio requer ponderar as implicações que se colocam num rol de situações da prática etnográfica, como: i) a profusão de "vozes" registradas em áudio, vídeo, desenhos, etc., e as decisões sobre o que selecionar e usar/ poderá divulgar e quão (im)parciais serão; ii) os efeitos éticos e epistemológicos da ampla e fácil circulação de informações no mundo virtual vs. restrita divulgação no mundo real; iii) o recorrente uso de nomes fictícios para pessoas e lugares na apresentação dos resultados da pesquisa; iv) a crescente burocratização do processo de entrada e permanência no terreno e quais os dados a que o etnógrafo terá acesso; v) os atuais condicionalismos temporais que impendem sobre a academia.

Por fim, queremos regressar, ainda, às recensões que têm estado na origem dos novos paradigmas para o estudo da infância nas várias disciplinas das ciências sociais para relembrar que raramente incluem a produção feita em outras línguas que não a inglesa. Não estando em causa o tremendo esforço deste tipo de levantamento e síntese metateórica, desde logo pela vastidão geográfica e temporal dos trabalhos e sua dispersão disciplinar, parece-nos ser a própria construção epistemológica sobre as crianças e a infância que fica a perder. A inclusão de contribuições que prezam pela diversidade de perspectivas e de contextos de pesquisa menos dominantes e talvez menos padronizados ajudaria a relativizar o conhecimento que se está construindo na Europa e na América do Norte sobre a infância e as crianças no mundo (Nunes 2003, p. 85-86; Carvalho; Nunes, 2009). Esta falta de interlocução convida-nos a refletir sobre a desigual circulação e troca de conhecimento e, ao mesmo tempo, a dedicar um olhar mais atento, em ambos os sentidos, a estas contribuições e às implicações epistemológicas de cada uma delas. 


\section{Referências}

ALDERSON, Priscilla; MORROW, Virginia. Ethics, social research and consulting with children and young people. London: Tanners Lane, Barnardo's. 2004.

BIRBECK, David; DRUMMOND, Murray. Interviewing, and listening to the voices of, very young children on body image and perceptions of self. Early Child Development and Care, v. 175, Issue 6, 2005. p. 579-596.

CAMERA, Hildair. Do olhar que convoca ao sorriso que responde: possibilidades interativas entre bebês. Dissertação (Mestrado em Educação)- Universidade Federal do Rio Grande do Sul, Porto Alegre, 2006.

CAPUTO, Virginia. Anthropology's silent "others": a consideration of some conceptual and methodological issues for the study of youth and children's cultures. In: AMIT-TALAI, Vered; WULFF, Helen (Org.). Youth Cultures: a Crosscultural Perspective. London: Routledge, 1995. p. 19-42.

CHRISTENSEN, Pia; JAMES, Allison. Research with children: perspectives and practices. London: Falmer Press, 2000.

COCKS, Alison. The ethical maze: finding an inclusive path towards gaining children's agreement to research participation. Childhood, v. 13, n. 2, p. 247-266, maio 2006.

COLONA, Elena. "Eu é que fico com a minha irmã" - vida quotidiana das crianças na periferia de Maputo. 2011. Tese (Doutorado em Estudos da Criança)- Instituto de Educação, Universidade do Minho, 2011.

CORSARO, William. Friendship and peer culture in the early years. Norwood: Ablex Publishing Corporation, 1985.

Sociology of childhood. London: Pine Forge, 1997.

CURRENT SOCIOLOGY, special issue, mar. 2010.

DAVIES, Brownyn. Frogs and snails and feminist tales: preschool children and gender. Sydney: Allen \& Unwin PTY Ltd., 1989.

DELALANDE, Julie. La cour de récréation, pour une anthropologie de l'enfance. Rennes: PUR, 2001.

DELGADO, Ana Cristina Coll. Estudos Antropológicos da Infância no Brasil, caminhos problematizações e diálogos. In: FILHO, Altino; PRADO, Patrícia. Das pesquisas com crianças à complexidade da infância. Campinas: Autores Associados, 2011. p. 181-210.

DEROUET, Jean-Louis; HENRIOT-VAN ZANTEN, Agnès; SIROTA, Régine. Approches ethnographiques en sociologie de l'éducation: l'école et la communauté, l'établissement scolaire, la classe. Note de synthèse. Revue Française de Pedagogie, n. 80, jul.-ago.-set., p. 69-97, 1987.

FERREIRA, Manuela. "A gente aqui o que gosta mais é de brincar com os outros 
meninos!" - as crianças como actores sociais e a (re)organização social do grupo de pares no cotidiano de um Jardim de Infância". 2002. Tese (Doutorado)- Faculdade de Psicologia e Ciências da Educação, Universidade do Porto, 2002.

; ROCHA, Cristina. "Vou fazer seis anos! Queres vir à minha festa?" A construção sócio-cultural do aniversário: valores, práticas sociais em contextos de Jardim de Infância e famílias de meio rural e urbano". In: CONGRESSO INTERNACIONAL MUNDOS SOCIAIS E CULTURASIS DA INFÂNCIA. Actas... Braga, Universidade do Minho, p. 356-372, 2000.

Olhares da sociologia sobre a infância, as crianças e a sua educação na produção académica nacional (1995-2005): balanço crítico e contributos da Sociologia da Infância, Encontro Contextos Educativos na Sociedade Contemporânea, APS, 2009. Disponível em: <www.aps.pt/?area=013>. Acesso em: 26 nov. 2013.

As crianças na escola e a reconstituição do seu ofício como alunos/as - análise da produção académica nacional (1995-2005): campos disciplinares, instituições e temáticas. Comparências, ausências e prelúdios. Revista da Sociedade Portuguesa de Ciências da Educação, n. 6/7, 2007/2008, p. 15-126, 2010.

Figures de l'enfance, des enfants et leur éducation dans la production universitaire portugaise (1995-2005): quelle est la contribution de la sociologie de l'enfance? - analyse critique. In: BRABANT, Louise Hamelin; TURMEL, André (Dir.) Les figures de l'enfance d'hier à aujourd'hui: un regard sociologique, Québec: Québec Presses Interuniversitaires, 2012. p. 205-222.

As crianças, a infância e a educação na produção académica nacional, nas universidades públicas e privadas. Portugal 1995-2005. Porto: CIIE/FCT/Livpsic, 2013. (no prelo).

GEERTZ, Cliford. A interpretação das culturas. Rio de Janeiro: Zahar Editores, 1978. GORDON, Tuula; HOLLAND, Janet; LAHELMA, Elina. Ethnographic research in educational settings. In: ATKINSON, Paul et al. Handbook of Ethnography. London: Sage, 2001. p.188-203.

GOTTLIEB, Alma. Where have all the babies gone? Towards an Anthropology of infants (and their caretakers). Anthropological Quarterly, v. 73, n. 3, 121-132, jul. 2000.

GUIMARÃES, Daniela. Relações entre bebês e adultos na creche: o cuidado como ética. São Paulo: Cortez Editora, 2011.

HARDMAN, Charlotte. Can there be an anthropology of children? Journal of the Anthropology Society Oxford 4 (1), 1973. p. 85-99.

HIRSCHFELD, Lawrence. Why don't anthropologists like children? American Anthropologist, v. 104, n. 2, 611-627, jun. 2002.

HOLLOWAY, Sarah; VALENTINE, Gill. Children's geographies, playing, living, learning. London: Routledge, 2000. 
JAMES, Allison. Childhood identities, self and social relationships in the experience of the child. Cambridge: Edinburgh University Press, 1993.

Ethnography in the study of children and childhood, In: ATKINSON, Paul et al. Handbook of Ethnography. London: Sage, 2001. p. 246-257.

Give a voice to children's voice: practices and problems, pitfalls and potentials. American Anthropology, v. 109, n. 2, p. 261-272, jun. 2007.

; JENKS, Chris; PROUT, Alan. Theorising childhood. London: Polity Press, 1998.

JAMES, Allison, PROUT, Alan. Constructing and Reconstructing Childhood, Contemporary Issues in the Study of Childhood. London: Falmer Press, 1997.

JOHANSSON, Barbo. Doing adulthood in childhood research. Childhood, v. 19, n. 1, p. 101-104, set. 2011.

LANCY, David. The Anthropology of Childhood: cherubs, chattel, changelings. New York: Cambridge University Press, 2009.

. Unmasking Children's Agency. AnthropoChildren, Issue 2, 2012. Disponível em: <http://popups.ulg.ac.be/AnthropoChildren/document.php?id=1253>. Acesso em: 26 nov. 2013.

LeVINE, Robert. Ethnographic studies of childhood: a historical overview. American Anthropology, v. 109, n. 2, p. 247-260, June. 2007.

MACKAY, Robert W. Conceptions of chidren and models of socialization. In: WAKSLER, Frances C. (Ed.) Studying the Social Worlds of Children: sociological readings. London: Falmer Press, 1991. p. 23-37.

MARTINS FILHO, Altino. Jeitos de ser criança: balanço de uma década de pesquisas com crianças, apresentadas na ANPED. In: MARTINS FILHO, Altino; PRADO, Patrícia. Das pesquisas com crianças à complexidade da infância. Campinas: Autores Associados, 2011. p. 81-106.

NUNES, Ângela. A sociedade das crianças A'uwe-Xavante: por uma antropologia da criança. Lisboa: Ministério da Educação, Instituto de Inovação Educacional, 1999.

- Brincando de ser criança: contribuições da etnologia indígena brasileira à antropologia da infância. 2003. Tese (Doutorado)- ISCTE, Portugal, 2003. Disponível em: <http://repositorio-iul.iscte.pt/handle/10071/684>. Acesso em: 26 nov. 2013.

. Can ethnography and participant observation help raise voice, agency and protagonism? Notes from fieldwork with Portuguese children in Germany. In: Migrants' Children, Migrant Children \& Inter-Ethnic Relations in the XXIst century. Presses Universitaires de Liège, 2013. (no prelo).

; CARVALHO, Rosário. Questões metodológicas e epistemológicas suscitadas pela Antropologia da Infância. BIB/ANPOCS, n. 68, p. 77-97, 2009.

OLIVEIRA, Allessandra M. R. Do outro lado. A infância sob o olhar de crianças no interior da creche. 2001. Dissertação (Mestrado em Educação)- UFSC, 
Florianópolis, 2001.

PIRES, Liliana. “Eu mandava limpar o bairro todo...”, (contra)tempos da participação infantil. Contributos da análise da participação das crianças nos tempos livres. 2004. Dissertação (Mestrado)- Faculdade de Psicologia e Ciências da Educação, Universidade do Porto, 2004.

PROUT, Alan. Foreword. In: CHRISTENSEN, Pia; JAMES, Allison (Eds.), Research with children: perspectives and practices. London: Falmer Press, 2002. p. xi-xii.

The future of Childhood: towards the interdisciplinary study of children. London: RoutledgeFalmer, 2005.

QUEIRÓS, Augusta. The Camelot Park - aniversários de crianças vividos em espaços de diversão - rituais contemporâneos para/da infância". 2009. Dissertação (Mestrado)- Faculdade de Psicologia e Ciências da Educação, Universidade do Porto, 2009.

QVORTRUP, Jens. Foreword. In: BRANNEN, Judith; O'BRIEN, Margareth. Children in families, policy and research. London: The Falmer Press, 1996. p. xi-xiii.

ROCHA, Eloisa. A pesquisa na educação infantil no Brasil: trajectória recente e perspectivas de consolidação de uma pedagogia da educação infantil. 1999. Tese (Doutorado)- Centro de Ciências da Educação, Universidade Federal de Santa Catarina, 1999.

; KRAMER, Sónia. (Org.). Educação infantil. Enfoques em diálogo. pedagógicas. Campinas, SP: Papirus, 2011.

SCALABRIN, Angela. As crianças no interior da creche: a educação e o cuidado nos momentos de sono, higiene e alimentação. 2002. Dissertação (Mestrado em Educação)- UFSC, Florianópolis, 2002.

“A acção social dos bebés - um estudo etnográfico no contexto da creche". 2010. Tese (Doutorado em Estudos da Criança)- Instituto de Educação, Universidade do Minho, 2010.

SILVA, Pedro. A etnografia vista através de um sociólogo da educação. In: CONGRESSO INTERNACIONAL DE ETNOGRAFIA E EDUCAÇÃO, II, 2007. Anais... Universidad Autónoma de Barcelona, 2007.

SCHMITT, Rosinete. Mas eu não falo a língua deles! As relações sociais de bebês em creche. 2008. Dissertação (Mestrado em Educação)- UFSC, Florianópolis, 2008.

SOLBERG, Ann. The challenge in children research: from "being" to "doing". In: BRANNEN, Judith; O'BRIEN, Margareth. Children in families, policy and research. London: Falmer Press, 1996. p. 53-65.

SZULC, Andrea; COHN, Clarice. Anthropology and Childhood in South America: Perspectives from Brazil and Argentina. AnthropoChildren, Issue 1, jan. 2012. Disponível em: <http://popups.ulg.ac.be/AnthropoChildren/document. php?id=427>. Acesso em: 26 nov. 2013. 
TISDALL, E. Kay M.; PUNCH, Samantha. Not so "new"? Looking critically at childhood studies. Children's Geographies, v. 10, n. 3, p. 249-264, ago. 2012.

THORNE, Barrie. Gender play, girls and boys in school. London: Open University Press, 1993.

TOREN, Christina. Making History: the Significance of Childhood Cognition for a Comparative Anthropology of Mind. Man, v. 28, n. 3, p. 461-478, set. 1993.

. Anthropology as the whole science of what is to be human. In: FOX, Richard

G.; KING, Barbara J. (Eds.). Anthropology beyond culture. New York: Oxford, 2002.

p. 105-124.

UPRICHARD, Emma. Children as 'being and becomings': children, childhood and temporality. Children \& Society, v. 22, n. 4, p. 303-313, jul. 2008.

WOODHEAD, Martin. Child development and the development of childhood. In: QVORTRUP, Jens; CORSARO, William, HONIG, Michael-Sebastian (Ed.). Handbook of childhood studies. London: Palgrave, 2009. p. 46-61.

Recebido em julho de 2013

Aprovado em novembro de 2013

Manuela Ferreira é professora associada da Faculdade de Psicologia e Ciências da Educação e pesquisadora do Centro de Investigação e Intervenção Educativa, em Portugal. E-mail: manuelađafpce.up.pt.

Ângela Nunes é doutora em Antropologia da Educação pelo Instituto Universitário de Lisboa e pesquisadora no Centro em Rede de Investigação em Antropologia, em Portugal. E-mail: angelannslagmail.com. 